\title{
A General Framework for Determining the Temporal and Evolutionary Dynamics of Religion-Based Website Popularity on the Internet
}

\author{
Michael R. Golinski ${ }^{1}$, Connie Petersen ${ }^{2}$ \\ ${ }^{1}$ Energy Research Laboratory, New Mexico State University, Las Cruces, USA \\ ${ }^{2}$ Department of Sociology, New Mexico State University, Las Cruces, USA \\ Email:mgolinsk@nmsu.edu, crpg1950@nmsu.edu
}

Received June 29, 2012; revised July 30, 2012; accepted August 12, 2012

\begin{abstract}
Religion-based websites are fast becoming a major pipeline for disseminating religious information to broad populations of individuals in the United States. Both mainstream religions and fringe religions are easily accessible to a large population of internet users. The purpose of this review is to develop and examine a general framework that uses simple mathematical and statistical models to interpret and measure temporal "snap shots" in the popularity of religious websites. We extend this framework to include an evolutionary model that has the potential to predict long-term shifts or changes in the popularity of religious websites over time. Ultimately, the goal of this review is to introduce a new modeling framework for research into how the internet is changing the accessibility and views of populations of individuals who follow various religions on the internet and how this may in-turn affect the distribution of religion in the "real world”.
\end{abstract}

Keywords: Communities; Drift; Evolution; Fringe Religion; Internet; Mainstream Religion; Powerlaw; Selection; Website

\section{Introduction}

The aims of this paper are to propose a general framework for using statistical and mathematical models to determine if increases over time in the popularity of religion-based websites in the United States results in the emergence of relatively large scale internet "communities" composed of individuals who follow "fringe" religions. Based on the aims of this general study, we define popularity as a measure of the website's visibility to an individual searching the internet. Within the context of this general overview, an internet-based community is defined as a social network of individuals who interact through specific websites [1]. We define "mainstream" religion practiced in the United States and promoted by the internet as Islam, Judaism, Buddhism, Spiritism, Christianity and Hinduism [2]. "Fringe" religions as practiced in the United States and promoted by the internet include but are not limited to Neo-Paganism, Rastafarianism, Scientology, New Age, Christian Scientist and a large number of so-called "cult" religions [3]. This general overview also considers changes over time in the popularity of non-mainstream web-based religions whose visibility to individual internet users falls somewhere between the visibility of websites that promote main- stream and fringe religions. Ultimately, the long-term aim of this paper described herein is to develop a general framework that can be used to describe short-term patterns in the popularity of religion-based websites and to determine if these patterns manifest themselves as longterm evolutionary shifts in the popularity in internet based religions. We believe that such a shift could result in the redistribution of religious websites on the internet, with less popular non-mainstream and fringe religionbased websites becoming as popular as mainstream websites over time.

Just as with non-internet based religious communities, we assume that generally speaking, religion-based internet communities are composed of individuals that follow different internet-based religions that are motivated by several factors, including: 1) The ability of the community to provide a source of group identity, individual identity, and impersonal social interaction; 2) The ability of the community to provide a philosophical and ethical framework, and the language through which philosophy, ethics and community issues can be discussed; 3) The ability of the community to provide a source of unity necessary for defense of the community and its ideals; 4) The ability of the community to address universal ex- 
periences such as death, sexuality, and family life.

Though sparse, there have been studies that show that the numbers of individuals that follow websites devoted to non-mainstream and fringe religion are small relative to the number of individuals that follow websites devoted to mainstream religion [4]. The relative acceptance of an ideology promoted by a religion-based website, as measured by the number of web hits the website receives over relatively short periods of time, may become mainstream, non-mainstream or fringe on a larger-scale with respect to the internet based community. There have been multiple studies that show that diverse cultural phenomena, including change in the frequency of archaeological pottery motifs over time [5] change in the frequency of baby names in the United States during the twentieth century [6] and change in the frequency of the number of times United States patents have been cited since 1963 exhibit a "long-tailed" distribution [7].

\section{Snap Shot Models}

Within the context of this paper, the long-tail distribution suggests that rather than one dominant religious website giving way to another over time, there may be many different choices of religion-based websites at all times. Mathematically, the highly skewed long-tail distribution is described by a simple power-law equation:

$$
P(V)=C / V^{\alpha}
$$

where $\alpha$ and $C$ are constants and $V>0$. In Equation (1), $P(V)$ is the proportion of web hits (out of all hits for all religion-based websites) that a religion-based website receives over time and $V$ is the number of religion-based websites (variants) in order of decreasing popularity. The power-law distribution described by Equation (1) and illustrated in Figure 1 is called the Pareto power-law [8], and it has been used in many scientific and sociological fields to describe temporal changes in the frequency of natural and sociological phenomena [9].

In one of the few studies of temporal changes in ecommerce patterns on the web [10], used the long-tail distribution to describe how most internet purchases in the United States congregate under the left side or normally distributed "buldge", while a large group of internet purchases for unpopular products tends to congregate under the long-tail of the distribution. $5 \%$ of the total number of web hits for all religion-based websites.

This type of pattern indicates that while there are many more unpopular variants than popular variants, the very few popular variants are thousands of times more popular than the unpopular variants.

Of key importance for the purposes of constructing a general framework, is that Anderson did not demonstrate how temporal change in e-commerce patterns in the United States is affected by website visibility. Specifically, he did not demonstrate if temporal patterns in internet purchases could change as more and more individuals that buy less popular items (those in the right side of the

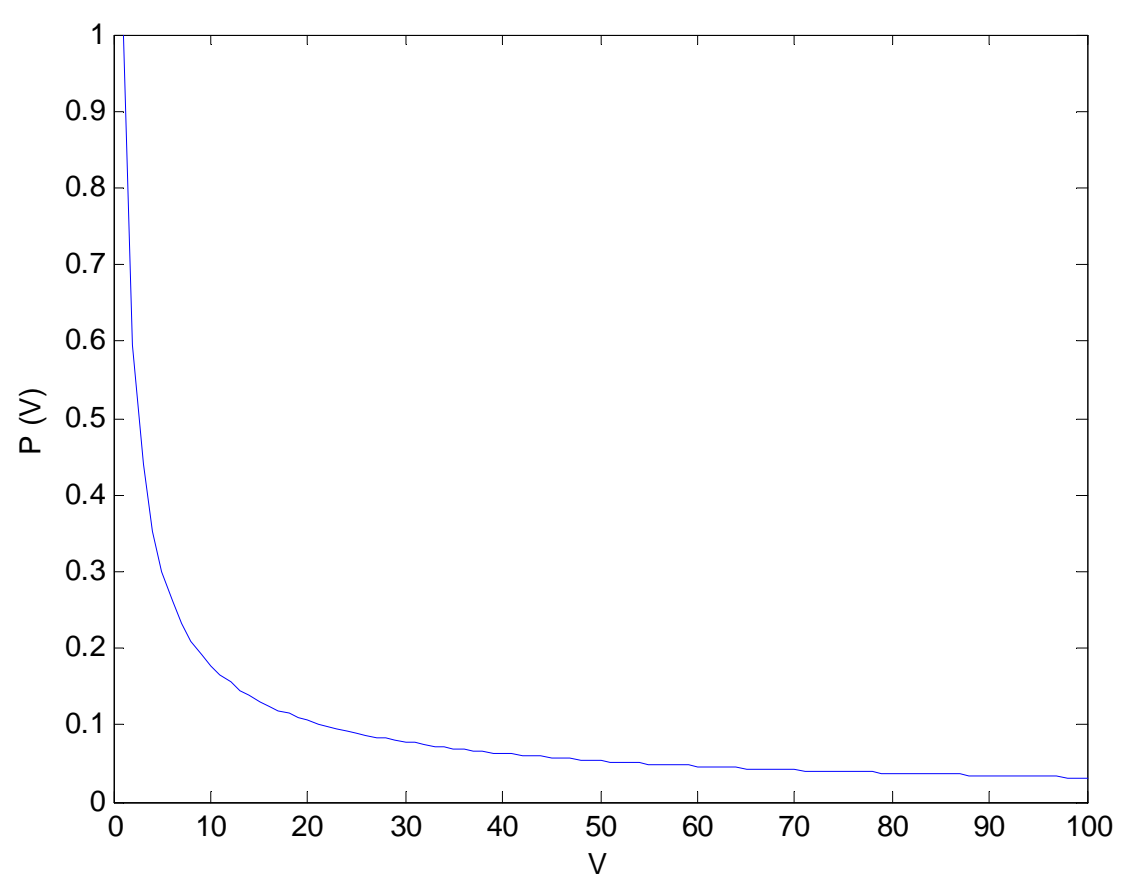

Figure 1. Long-tail distribution generated by Equation (1). $P(V)$ is the proportion of web hits (out all hits for all religion-based websites) that a religion-based website receives over time as a function of the number of religion-based websites in order of decreasing popularity $V$. In the figure, the 100th website receives approximately $1 \%$ of the total number of web hits for all religion-based websites. In the figure, $C=2.2$ and $\alpha=1.15$ in $P(V)$. 
long-tail distribution) begin to purchase more and more of a select number of unpopular products, thus increasing the proportion of those products being purchased over time.

Therefore, we believe that future research should address the following: 1 ) Does the distribution of the observed proportion of web hits that religion-based websites receive over time follow the power-law distribution described by Equation (1). 2) Can simple mathematical and statistical models be developed and used to extend Anderson's work to explore the hypothesis that increased visibility of religion-based websites to individual internet users facilitates an increase in the proportion of web hits that those websites receive, resulting in a cultural shift in internet-based religion over relatively long periods of time. We hypothesize that such a shift could result in a redistribution of religion-based websites on the internet, with less popular non-mainstream and fringe religionbased websites becoming as popular as mainstream religion-based websites over time.

To begin to test these hypotheses and accomplish the goals laid out in this paper, we call upon researchers with expertise in statistical and mathematical modeling to communicate their work to experts in ethics and technology, whose work combines the fields of science and technology studies, ethics and public policy. Integration of work from these disciplines could lead to a better understanding of both the interconnected relationships between technology, society, and the forces that change those relationships over time.

\section{Modeling the Evolution of Religion-Based Websites}

While Equation (1) can be used to construct a temporal "snap shot" of the phenomenon of religion-based website usage, the casual mechanisms for change i.e. how this phenomena manifests itself in over relatively long periods of time, can only be addressed with appropriate mathematical and statistical models. In order to accomplish this would require future development of models that can be used to predict mechanisms that shape the short-term and long-term temporal dynamics of internet-based religion.

There are many documented examples of cultural change in situations where, rather than one dominant cultural variant giving way to another over time, there are many different choices available at all times [9]. This pattern is analogous to the pattern of genetic drift through random copying described by population genetics, and is referred to as the neutral model [11] because the variants are considered neutral with respect to the success of the individual. The process of random genetic drift, which is characterized by the long-tail power-law distribution described by Equation (1), relates temporal change in the proportion of a cultural "type" as a function of the number of cultural variants in that population. The skewness of the distribution indicates that the process of random copying dominates temporal change in the diversity of variants over time [9]. Deviation of cultural change from the long-tail distribution may indicate selection for specific variants over time [5,6,12,13].

Within the context of this paper, Equation (1) describes a property that characterizes "neutral" evolution of religion-based websites in the United States population. Hence, the power-law equation predicts that there are many uncommon religion-based websites and a very few popular religion-based websites that are thousands of times more popular than the majority (long-tail of the distribution). While information generated by the shape of the powerlaw distribution is useful in describing shortterm trends in the popularity of religion-based websites on the internet, it does not tell us how these short-term patterns manifest themselves of longer time periods.

Under our proposed hypothesis, increased visibility over time of non-mainstream and fringe religion-based websites to individual internet users could facilitate an increase in the proportion of web hits (out all hits for all religion-based websites) that the religion-based websites receives, resulting in a cultural shift in internet-based religion. We propose that such a shift could result in a redistribution of religion-based websites on the internet, with less popular religion-based websites becoming as popular as mainstream websites over time (Figure 2). Therefore, we make the claim that future mathematical and statistical model(s) that are developed to address this hypothesis must assume that the mechanism leading to increases over time in the popularity of websites that promote non-mainstream and fringe religion is selection, not genetic drift.

In Figure 2, increasing values of time $\left(t_{1}, \cdots, t_{3}\right)$ show changes in the popularity of fringe religious websites i.e. the area under the curve increases over time. While popular websites remain popular over time, selection begins to act on fringe websites, increasing their popularity over time. For ever increasing time, selection should act to continue to increase the popularity of fringe websites, which may result in a cultural shift, where fringe websites begin to become as popular as mainstream websites.

\section{Methods and Conclusion}

In order to strengthen the testability of the hypotheses outlined in this paper requires that future research focus on religion-based websites whose sole purpose is to promote their religious ideology. Therefore, data used in future research should be based explicitly on religionbased websites that are well organized and provide content specific to the promotion of that religion. To 


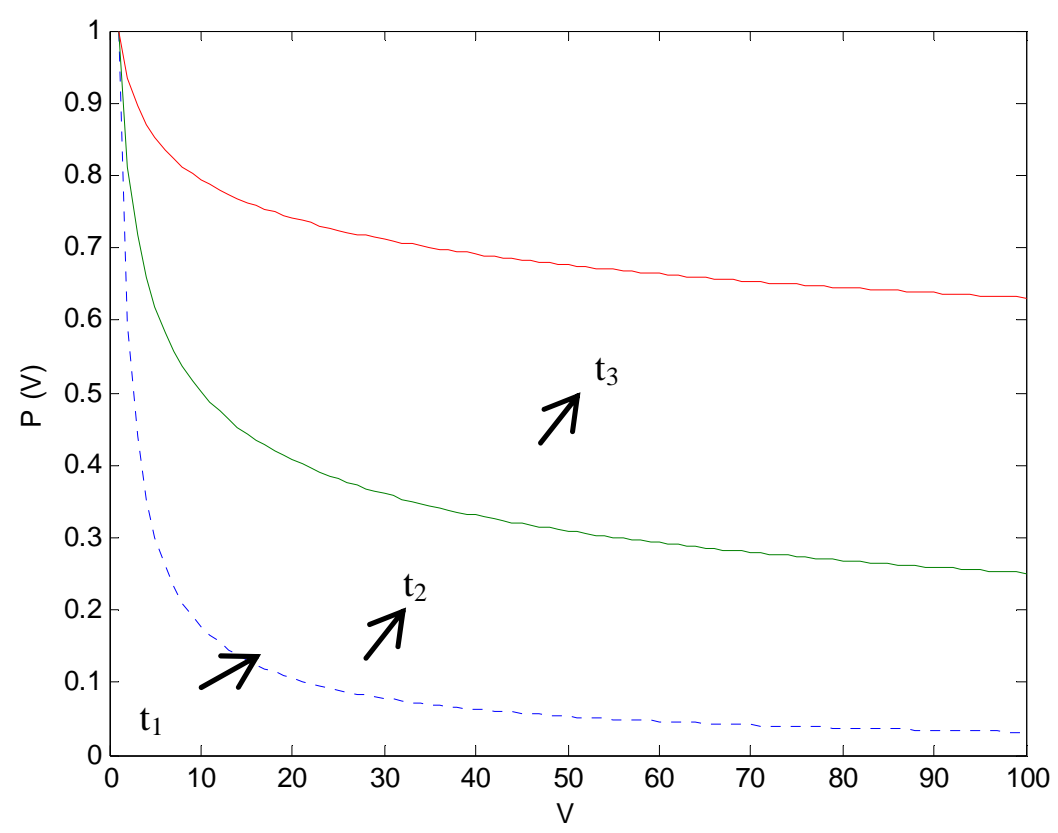

Figure 2. Prediction of a model if selection drives temporal change in the proportion $P(V)$ of web hits (out all hits for all religion-based websites) that a religion-based website receives over time as a function of the number of religion-based websites in order of decreasing popularity $(V)$. Increased visibility of unpopular religion-based websites (non-mainstream and fringe) to individual internet users could result in a cultural shift in internet-based religion over time $\left(t_{1}, \cdots, t_{3}\right)$. As time increases from $t_{1}$ to $t_{3}$, selection acts to increase the proportion of web hits initially unpopular religion-based websites receive. In the figure, $t_{1}$ is approximately $0.20, t_{2}$ is approximately 0.40 , and $t_{3}$ is approximately 0.70 .

quantify increased visibility of religion-based websites in the United States requires that these studies measure the number of web hits that religion-based websites received over an extended period of time, and use this as a proxy for quantifying popularity. With this information, future research should focus on constructing a probability distribution that describes the relationship between the observed proportions of web hits (out all hits for all religion-based websites) that a religion-based website receives over time as a function of the number of religionbased websites in order of decreasing popularity. For example, in order to quantify differences in the popularity of different religion-based websites, future studies could measure the proportion of web hits that each website receives over a specified period of time (e.g. one year, two years, etc.). If the proportion of web hits that a website receives over time ranges from $20 \%$ to $100 \%$, it will be classified as a mainstream religion-based website, if the proportion is less than $20 \%$ but greater than $10 \%$, it will be classified as non-mainstream, and if the proportion is less than $10 \%$ it be classified as fringe. If our hypothesis is correct, the distribution will follow the power-law distribution described by Equation (1). Presently, several statistical software packages exist for analyzing the number of hits that websites receive over time, including Flow Analytics ${ }^{\mathrm{TM}}$ and Solarwinds ${ }^{\mathrm{TM}}$ network flow analyzer. These types of software packages and others can be used to capture and analyze data in real time to show the number of web hits that religion-based websites receive over time. Based on the distribution of the number of web hits that religion-based websites receive over time, future studies should construct mathematical models to predict if neutral or selective forces are more likely to drive the redistribution of religion-based websites over time, and how this redistribution could shape the demographics of religion among technologybased societies.

\section{Acknowledgements}

The author's would like to thank Dr. Jameson Wetmore (Assistant Professor, School of Human Evolution and Social Change, College of Liberal Arts and Sciences. Arizona State University) for his insight.

\section{REFERENCES}

[1] H. Rheingold, "The Virtual Community: Homesteading on the Electronic Frontier,” MIT Press, London, 2000.

[2] D. B. Barret, G. T. Kurian and T. M. Johnson, "World Christian Encyclopedia: A Comparative Survey of Churches and Religions in the Modern World Volume 1: The World by Countries: Religionists, Churches, Ministries,” Oxford University Press, Oxford, 2001.

[3] L. Lorne, L. L. Dawson and D. E. Cowan, "Religion Online: Finding Faith on the Internet,” Routledge, London, 2004. 
[4] C. Helland, "Popular Religion and the World Wide Web: A Match Made in (Cyber) Heaven,” In: L. L. Dawson and D. E. Cowan, Eds., Religion Online: Finding Faith on the Internet, Routledge, London, 2004, pp. 23-35.

[5] S. J. Shennan and J. R. Wilkinson, "Ceramic style change and Neutral Evolution: A Case Study from Neolithic Europe," American Antiquity, Vol. 66, No. 4, 2001, pp. 577-594. doi:10.2307/2694174

[6] M. W. Hahn and R. A. Bentley, "Drift as a Mechanism for Cultural Change: An Example from Baby Names," Proceedings of the Royal Society A, Vol. 270, No. 1, 2003, pp. S120-S123. doi:10.1098/rsbl.2003.0045

[7] B. H. Hall, A. B. Jaffe and M. Trajtenberg, "The NBER Patent Citations Data File: Lessons, Insights and Methodological Tools,” In: M. Trajtenberg, Ed., Patents, Citations, and Innovations: A Window on the Knowledge Economy, MIT Press, Cambridge, 2002, pp. 403-460.

[8] W. Reed, "The Pareto, Zipf and Other Power Laws," Economics Letters, Vol. 74, No. 1, 2001, pp. 15-19. doi:10.1016/S0165-1765(01)00524-9
[9] R. A. Bentley, C. P. Lipo, H. A. Herzog and M. W. Hahn, "Regular Rates of Popular Culture Change Reflect Random Copying," Evolution and Human Behavior, Vol. 28, No. 3, 2007, pp. 151-158. doi:10.1016/j.evolhumbehav.2006.10.002

[10] C. Anderson, "The Long Tail: Why the Future of Business Is Selling Less of More,” Hyperion, New York, 2006.

[11] J. F. Crow and M. Kimura, "An Introduction to Population Genetics Theory,” Harper and Row, New York, 1970.

[12] F. D. Neiman, "Stylistic Variation in Evolutionary Perspective: Inferences from Decorative Diversity and Inter-Assemblage Distance in Illinois Woodland Ceramic Assemblages,” American Antiquity, Vol. 60, No. 1, 1995, pp. 7-36. doi:10.2307/282074

[13] C. P. Lipo, M. E. Madsen, R. C. Dunnell and T. Hunt, "Population Structure, Cultural Transmission and Frequency Seriation,” Journal of Anthropological Archaeology, Vol. 16, 1997, pp. 301-333. doi:10.1006/jaar.1997.0314 